\title{
Impact of H3K27 Demethylase Inhibitor GSKJ4 on NSCLC Cells Alone and in Combination with Metformin
}

\author{
HIKARU WATARAI ${ }^{1,2^{*}}$, MASASHI OKADA $^{1 *}$, KENTA KURAMOTO $^{1}$, \\ HIROYUKI TAKEDA ${ }^{1,3}$, HIROTSUGU SAKAKI $^{1,4}$, SHUHEI SUZUKI ${ }^{1,3}$, SHIZUKA SEINO ${ }^{1,5}$, \\ HIROYUKI OIZUMI ${ }^{2}$, MITSUAKI SADAHIRO ${ }^{2}$ and CHIFUMI KITANAKA ${ }^{1,5}$ \\ Departments of ${ }^{1}$ Molecular Cancer Science, ${ }^{3}$ Obstetrics and Gynecology, ${ }^{4}$ Clinical Oncology and \\ ${ }^{2}$ Second Department of Surgery, Yamagata University School of Medicine, Yamagata, Japan; \\ ${ }^{5}$ Research Institute for Promotion of Medical Sciences, Yamagata University Faculty of Medicine, Yamagata, Japan
}

\begin{abstract}
Background: GSKJ4, an H3K27 demethylase inhibitor, reportedly exhibits antitumor activity against specific cancers harboring genetic alterations in genes encoding chromatin modulators. However, its potential as an anticancer agent against human cancers not associated with such genetic alterations, including non-small cell lung cancer (NSCLC), remains unknown. Materials and Methods: The effect of GSKJ4 on the growth of three NSCLC cell lines and normal lung fibroblasts was investigated using the WST8, dye exclusion, and colony formation assays. Results: GSKJ4, alone and in combination with an anti-diabetic drug metformin, induced cell death and inhibited the growth of NSCLC cell lines efficiently at concentrations non-toxic to normal cells, irrespective of their genetic backgrounds (mutations in the KRAS, TP53 and EGFR genes) and also of their resistance to cisplatin and paclitaxel. Conclusion: GSKJ4, being a promising anticancer agent for NSCLC, may be effective against a wider spectrum of cancers than previously thought.
\end{abstract}

Histone modification through lysine methylation plays a key role in the modulation of the chromatin structure and is, thus, involved in the control of a diverse array of cellular functions. The regulation of histone lysine methylation is

\footnotetext{
*These Authors contributed equally to this study.

Correspondence to: Chifumi Kitanaka and Masashi Okada, Department of Molecular Cancer Science, Yamagata University School of Medicine, Yamagata, 990-9585, Japan. Tel: +81 236285212, Fax: +81 236285215, e-mail: ckitanak@med.id.yamagata-u.ac.jp, mokada@med.id.yamagata-u.ac.jp
}

Key Words: Epigenetic, global histone modification, chemotherapy, clonogenic survival. governed by the balance between lysine methyltransferases (KMTs) and demethylases (KDMs), whereas dysregulation of histone lysine methylation has been described in a number of pathological conditions, including cancer (1-4). Accordingly, an increasing number of inhibitors against KMTs and KDMs are currently developed as therapeutic agents (5).

GSKJ4 is among such inhibitors and has been developed as a cell-permeable derivative of GSKJ1, an inhibitor of KDM6 subfamily demethylases JMJD3 and UTX, which catalyze the demethylasion of di- and tri-methylated lysine 27 of histone 3 (H3K27me2/3) (6). Recently, the anticancer effects of GSKJ4 were demonstrated against T-cell acute lymphoblastic leukemia (T-ALL) and pediatric brain stem glioma, in which genetic alterations causing reduced H3K27 methylation occur frequently (7-9). In T-ALL, loss of function mutations and deletions of the EZH2 and SUZ12 genes result in inactivation of the polycomb repressive complex 2 (PRC2), an H3K27 KMT complex, and, therefore, in reduced methylation of H3K27 (9). Similarly, in pediatric brainstem glioma, a mutation in the $H 3 F 3 A$ gene that causes a substitution of lysine 27 with methionine (K27M) has a dominant effect, sequestering PRC2 and reducing cellular H3K27 methylation (10-13). Importantly, GSKJ4 was ineffective against glioma cell lines that did not have the mutation (i.e., H3F3A K27M mutation) and showed high H3K27me3 levels, suggesting that the global H3K27me3 level may be a determinant of GSKJ4 sensitivity (8). More recently, since stem cells reportedly have decreased global H3K27me3 levels compared to differentiated cells, we tested the effect of GSKJ4 on cancer stem cells derived from ovarian cancer cells and revealed that GSKJ4 induces cell death and differentiation of ovarian cancer stem cells (14). Together, these studies, including ours, suggested that GSKJ4 may be effective against cancer cells with low H3K27me3 expression. However, to date, the anti-cancer 
effects of GSKJ4 on cancer cells in general, e.g., non-cancer stem cells of human cancers not necessarily associated with genetic alterations that directly affect $\mathrm{H} 3 \mathrm{~K} 27$ methylation, remain totally unknown.

Notably, it has been demonstrated in some human cancers that $\mathrm{H} 3 \mathrm{~K} 27 \mathrm{me} 3$ expression is decreased in cancerous tissues compared to the corresponding normal tissues from which they are derived (15-17). Non-small cell lung cancer (NSCLC) is one such cancer; a previous study demonstrated that, whereas $\mathrm{H} 3 \mathrm{~K} 27 \mathrm{me} 3$ was expressed at high levels in all normal lung tissues examined, its expression was decreased in NSCLC tissues (15). Importantly, it was also shown that H3K27me3 expression was lower in less differentiated NSCLC tumors, with low H3K27me3 expression being associated with poor survival (15). We, therefore, reasoned that GSKJ4 might possibly have anticancer effects against poorly differentiated NSCLC cells with low H3K27me3 expression.

In this study, we examined the effects of GSKJ4 on NSCLC cells. Our data showed that GSKJ4 exerts a potent growthinhibitory effect against NSCLC cells at concentrations not toxic to normal human cells. We also demonstrated that metformin effectively cooperates with GSKJ4 to inhibit the growth of NSCLC cells.

\section{Materials and Methods}

Antibodies and reagents. Antibodies against tri-methyl-histone $\mathrm{H} 3$ (Lys27) (\#9733), histone H3 (\#4499), GAPDH (\#5174), cleavedPARP (Asp214) (\#9541) and cleaved-caspase 3 (Asp175) (\#9661) were purchased from Cell Signaling Technology, Inc. (Beverly, MA, USA). GSKJ4 (ab144395) was purchased from Abcam (Cambridge, UK). Cisplatin and paclitaxel were purchased from Wako Pure Chemical Industries, Ltd. (Osaka, Japan). GSKJ4, cisplatin and paclitaxel were dissolved in dimethyl sulfoxide (DMSO) to prepare $10 \mathrm{mM}, 100 \mathrm{mM}$ and $1 \mathrm{mM}$ stock solutions, respectively. Metformin was purchased from Sigma-Aldrich (St. Louis, MO, USA) and was dissolved in phosphate-buffered saline (PBS) to prepare a $1 \mathrm{M}$ stock solution.

Cell culture. Human NSCLC cell lines A549, H1299 and PC9 were purchased from the Riken BioResource Center (Tsukuba, Japan). To verify the authenticity of the cells used in this study, the cells in actual use were subjected to genotyping by short tandem repeat (STR) profiling (Bio-Synthesis, Inc., Lewisville, TX, USA) followed by comparison with the American Type Culture Collection (ATCC) STR database for human cell lines. A549 and H1299 cells were maintained in DMEM/F12. PC9 cells were maintained in RPMI1640. Normal human IMR90 fetal lung fibroblasts were purchased from ATCC (Manassas, VA, USA) and maintained in DMEM. All culture media were supplemented with $10 \%$ fetal bovine serum, $100 \mathrm{U} / \mathrm{ml}$ penicillin and $100 \mu \mathrm{g} / \mathrm{ml}$ streptomycin. All IMR90 experiments were performed using low passage number $(<8)$ cells.

Cell viability assay. Cell viability was determined by tetrazolium salt reduction method using WST-8 according to the manufacturer's instructions (Cell Counting Kit-8; DOJINDO LABORATORIES,
Kumamoto, Japan) $(18,19)$. In brief, 5,000-8,000 cells/well were plated in 96-well tissue culture plates and, after $24 \mathrm{~h}$, were treated with drugs as described in the figure legends. Then, WST- 8 reagent was added and the cells were incubated for $3 \mathrm{~h}$ at $37^{\circ} \mathrm{C}$. Absorbance at $450 \mathrm{~nm}$ was measured using a spectral scanning multimode plate reader, Valioskan Flash (Thermo Scientific, Waltham, MA, USA). Relative cell viability was calculated as a percentage of absorbance of treated samples relative to that of controls.

Cell death assay. Dead cells were identified by their inability to exclude a vital dye, trypan blue $(14,20)$. To determine the number of viable and dead cells, cells were stained with $0.2 \%$ trypan blue and subjected to counting using a hemocytometer under a phasecontrast microscope.

Histone extraction. Histone extraction was performed using an acid extraction method as previously described (14). Cells were washed with chilled PBS once and lysed in hypotonic buffer $(10 \mathrm{mM}$ Hepes-KOH (pH 7.4), $10 \mathrm{mM} \mathrm{KCl}$ and $0.5 \% \mathrm{NP}-40$ ) for $10 \mathrm{~min}$ on ice. The cell lysates were then agitated by pipetting and centrifuged at $4,000 \times g$ for $10 \mathrm{~min}$ at $4^{\circ} \mathrm{C}$. After centrifugation, the precipitates were washed once in hypotonic buffer, re-suspended in $0.4 \mathrm{~N} \mathrm{HCl}$ and incubated overnight at $4^{\circ} \mathrm{C}$ under shaking conditions. The acid extracts were centrifuged at $14,000 \times \mathrm{g}$ for $10 \mathrm{~min}$ at $4^{\circ} \mathrm{C}$ and the supernatants were subsequently trichloroacetic acid-precipitated (final 33\%) and centrifuged at $14,000 \times g$ for $10 \mathrm{~min}$ at $4^{\circ} \mathrm{C}$ again. The precipitates were washed with ice-cold acetone for removing acid and centrifuged at $14,000 \times \mathrm{g}$ for $10 \mathrm{~min}$ at $4^{\circ} \mathrm{C}$. The pellets were air-dried at room temperature and re-suspended in urea buffer ( $2 \%$ sodium dodecyl sulfate (SDS), $10 \%$ glycerol, $60 \mathrm{mM}$ Tris- $\mathrm{HCl}$ ( $\mathrm{pH}$ 6.6), $4 \mathrm{M}$ urea and $0.5 \mathrm{mM}$ dithiothreitol) prior to being subjected to immunoblot analysis.

Immunoblot analysis. Immunoblot analysis was conducted as previously described (21). Briefly, cells were washed with ice-cold PBS and lysed in RIPA buffer (10 mM Tris- $\mathrm{HCl}(\mathrm{pH} 7.4), 0.1 \%$ SDS, $0.1 \%$ sodium deoxycholate, $1 \%$ NP- $40,150 \mathrm{mM} \mathrm{NaCl}, 1 \mathrm{mM}$ EDTA, $1.5 \mathrm{mM} \mathrm{Na} \mathrm{VO}_{4}, 10 \mathrm{mM} \mathrm{NaF}, 10 \mathrm{mM}$ sodium pyrophosphate, $10 \mathrm{mM}$ sodium $\beta$-glycerophosphate and $1 \%$ protease inhibitor cocktail set III (Sigma)). After centrifugation for $10 \mathrm{~min}$ at $14,000 \times g$ at $4^{\circ} \mathrm{C}$, the supernatants were recovered as cell lysates and the protein concentration of the cell lysates was determined by a BCA protein assay kit (Pierce Biotechnology Inc., Rockford, IL, USA). Cell lysates containing equal amounts of protein were separated by sodium dodecyl sulfate-polyacrylamide gel electrophoresis (SDS-PAGE) and transferred to a polyvinylidene difluoride membrane. Immunoreactive bands were visualized using Immobilon Western Chemiluminescent HRP Substrate (Millipore, Billerica, MA, USA). The membrane was probed with a primary antibody and then with an appropriate horseradish peroxidaseconjugated secondary antibody, according to the protocol recommended by the manufacturer of each antibody.

Flow cytometry analysis. Cell-cycle profiles were analyzed by the standard propidium iodide (PI) staining protocol. In brief, both adherent and non-adherent cells were collected and, after being washed once with PBS, fixed with cold $70 \%$ ethanol at $-20^{\circ} \mathrm{C}$ overnight or longer. After centrifugation for $10 \mathrm{~min}$ at $1,000 \times \mathrm{g}$, the pellets were washed with PBS twice. The cells were then incubated with PI $(20 \mu \mathrm{g} / \mathrm{ml})$ and RNase A $(10 \mu \mathrm{g} / \mathrm{ml})$ in PBS for 
$30 \mathrm{~min}$ at $37^{\circ} \mathrm{C}$ in the dark and subjected to flow cytometry analysis on EC800 (SONY, Tokyo, Japan). All collected data were analyzed using the FlowJo software, version 7.6.5 (Treestar Inc., Ashland, OR, USA).

Colony formation assay. Colony formation assay was performed as described previously $(22,23)$. In brief, cells seeded at a low, colonyforming density $\left(1-3 \times 10^{2}\right.$ cells $\left./ \mathrm{ml}\right)$ were treated and cultured as described in the figure legend. The cells were then fixed with formaldehyde $(4 \% \mathrm{v} / \mathrm{v})$, followed by staining with crystal violet $(0.1 \% \mathrm{w} / \mathrm{v})$. Colonies (consisting of $\geq 50$ cells derived from a single cell) were counted using a microscope.

Statistical analysis. Results are expressed as the mean and standard deviation (SD). Differences were compared using the two-tailed Student's $t$-test. $p$-Values $<0.05$ were considered statistically significant, as indicated with asterisks in the figures.

\section{Results}

Growth inhibitory effect of GSKJ4 on NSCLC cells with low H3K27me3 levels. To determine whether NSCLC cells cultured in vitro have lower global levels of $\mathrm{H} 3 \mathrm{~K} 27 \mathrm{me} 3$ than normal cells, NSCLC cell lines (A549, H1299, PC9) and human fetal lung fibroblasts (IMR90) were analyzed for H3K27me3 expression. The H3K27me3 levels of the three NSCLC cell lines were each lower than that of IMR90 cells (Figure 1), suggesting that NSCLC cells may maintain low global levels of $\mathrm{H} 3 \mathrm{~K} 27 \mathrm{me} 3$ in vitro as reported in vivo (15). Next, to determine whether GSKJ4 has an anticancer activity against such NSCLC cells with low H3K27me3 levels, we examined the effect of GSKJ4 on the growth of the NSCLC cell lines and IMR90. First, we exposed IMR90 cells to varying concentrations of GSKJ4 and examined their viability by assessing their metabolic activity to reduce WST-8 to a soluble formazan product (WST- 8 assay). The results of the WST- 8 assay indicated that IMR90 cells tolerated GSKJ4 up to $4 \mu \mathrm{M}$ (Figure 2A). We then examined, similarly, the impact of GSKJ4 treatment on the viability of NSCLC cells. Although there were some differences of sensitivity among the three NSCLC cell lines, GSKJ4 decreased cell viability in all of them significantly and substantially at $1 \mu \mathrm{M}$ and higher concentrations, within the range of concentration not toxic to IMR90 cells (Figure 2B). To examine the growth inhibitory effect of GSKJ4 in an independent manner and whether GSKJ4 has a cytotoxic effect on NSCLC cells as well, we examined cell viability using the dye exclusion method. Whereas GSKJ4 at lower concentrations $(\leq 1 \mu \mathrm{M})$ decreased the number of viable cells without inducing cell death, cell death was apparent when NSCLC cells were treated with GSKJ4 at higher concentrations ( $\geq 2 \mu \mathrm{M}$ ) (Figure $2 \mathrm{C}$ ), suggesting that the growth inhibitory effect of GSKJ4 may be cytostatic at lower concentrations, but that cytotoxicity contributes to its growth inhibitory effect at higher concentrations. Since

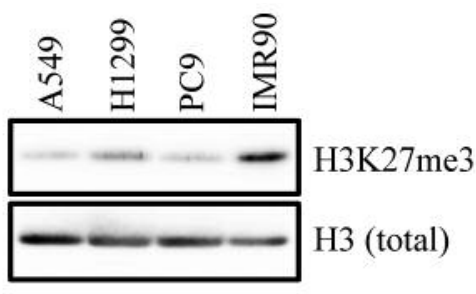

Figure 1. Expression of tri-methylated lysine 27 of histone $\mathrm{H3}$ (H3K27me3) in non-small cell lung cancer (NSCLC) cell lines and in normal human lung fibroblasts. The indicated NSCLC cell lines and IMR90 human fetal lung fibroblasts were subjected to immunoblot analysis after histone extraction to determine the global level of H3K27me3, as well as the total histone H3 level.

subsequent cell-cycle analysis demonstrated increase in the sub-G $\mathrm{G}_{1}$ population in NSCLC cells treated with $2 \mu \mathrm{M}$ GSKJ4 (Figure 3A), we examined whether the caspase pathway is activated in GSKJ4-treated NSCLC cells. GSKJ4 treatment induced cleavage of caspase 3 and PARP in proportion to cell death (Figure 3B), suggesting that apoptosis may be involved in the cytotoxic mechanism of GSKJ4. Thus, the data indicated that GSKJ4 induces apoptosis and inhibits the growth of NSCLC cells at concentrations not toxic to normal cells.

Suppression of clonogenic outgrowth of NSCLC cells by GSKJ4. Having demonstrated the growth inhibitory effect of GSKJ4 on NSCLC cells, we next asked whether the observed growth inhibitory effect has any therapeutic relevance and leads to decreased clonogenic survival. To examine the impact of GSKJ4 on the clonogenic outgrowth of NSCLC cells, we conducted a colony formation assay instead of evaluating cell viability at an early time point (3 days) after drug treatment as we did earlier (Figure 2). We treated the cells with GSKJ4 for 3 days and, then, allowed them to grow for an additional 6-day period in the absence of the drug, until the control-treated cells formed prominent colonies. In all three NSCLC lines, GSKJ4 effectively inhibited colony formation in a concentration-dependent manner (Figure 4), thus underscoring the therapeutic potential of GSKJ4.

The effect of GSKJ4 on the sensitivity of NSCLC cells to cisplatin and paclitaxel. The results obtained so far, in this study, indicated that GSKJ4 is effective against NSCLC cells when used alone. However, given the genome-wide influence GSKJ4 would have on H3K27 methylation and, hence, on gene transcription in general, it was quite unpredictable how GSKJ4 would affect the sensitivity of NSCLC cells, when used in combination with other therapeutic agents, such as cisplatin and paclitaxel. GSKJ4 
A

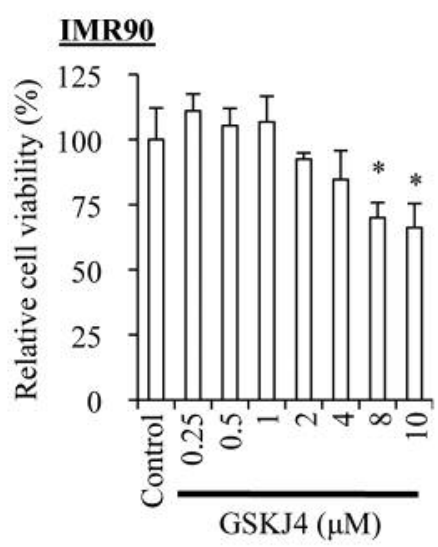

B

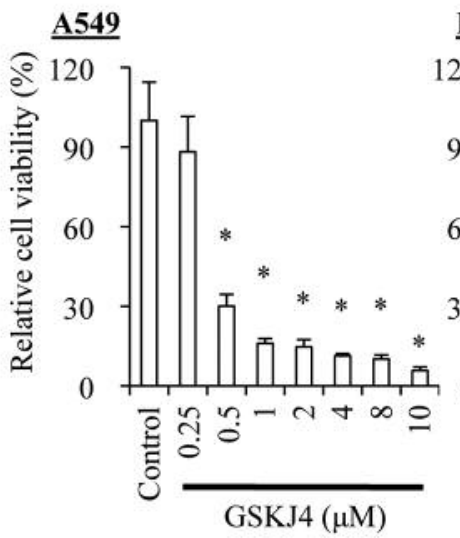

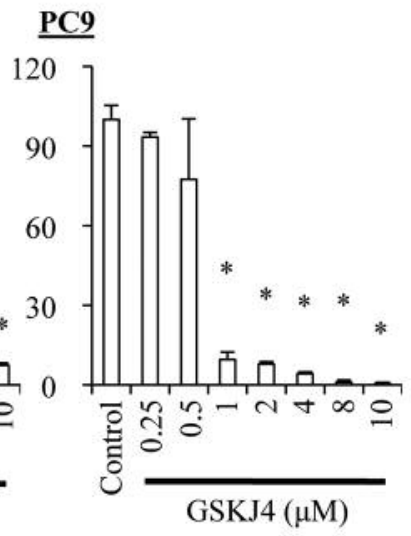
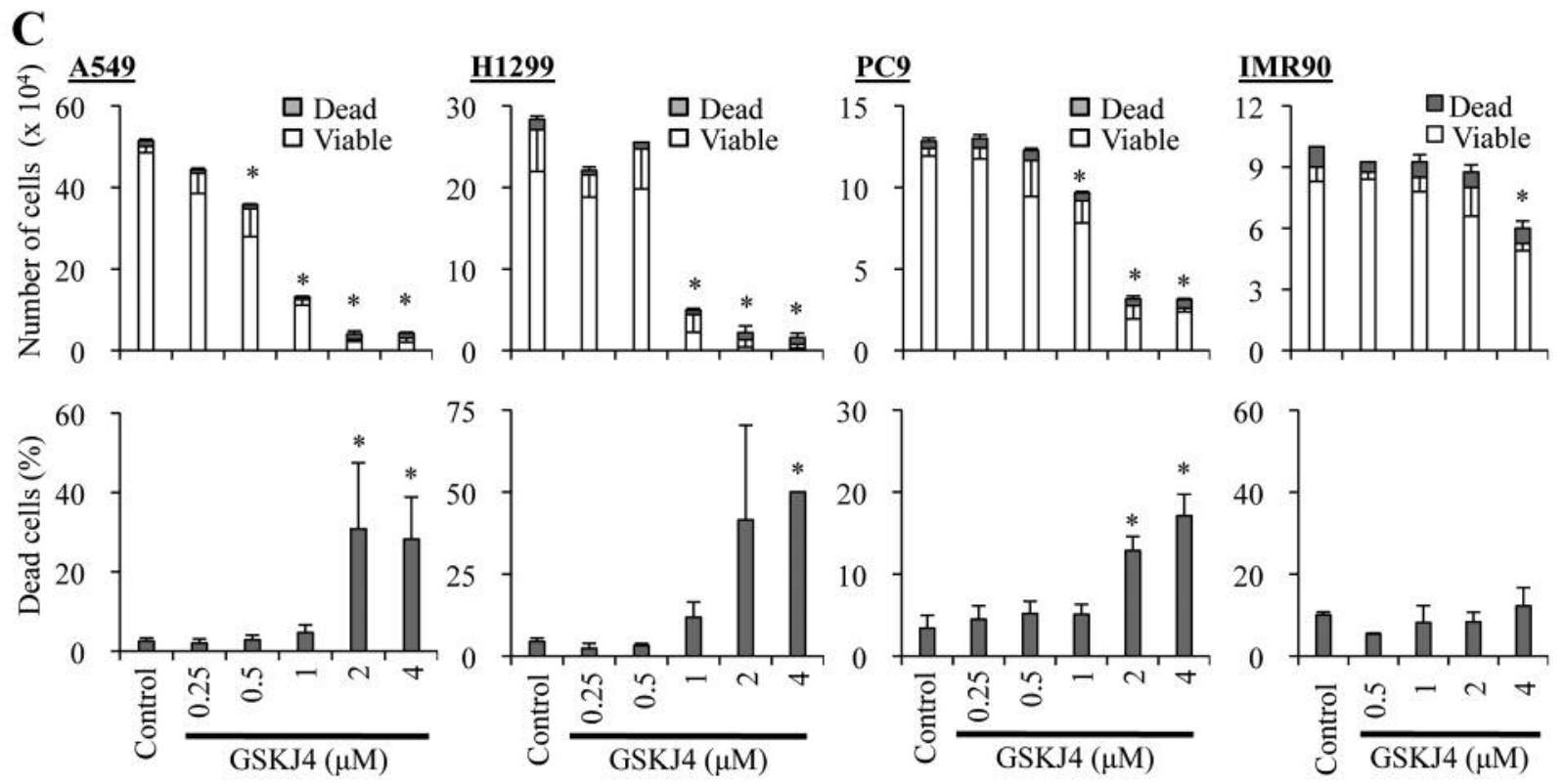

Figure 2. GSKJ4 selectively induces cell death and inhibits the growth of non-small cell lung cancer (NSCLC) cells. IMR90 human fetal lung fibroblasts (A) and the indicated NSCLC cell lines $(B)$ treated with the indicated concentrations of GSKJ4 for 3 days were subjected to the cell viability assay using WST-8. (C) Cells treated with the indicated concentrations of GSKJ4 were subjected to the cell death assay based on trypan blue dye exclusion method. The number of viable and dead cells (upper panels) and the percentage of dead cells (lower panels) are shown. In (A) through $(C)$, values in the graphs represent means $\pm S D$ from triplicate samples of a representative experiment repeated with similar results. ${ }^{*} p<0.05$.

could possibly augment cells' resistance mechanism(s) to these drugs, on one hand, while inhibiting the growth of NSCLC cells, on the other hand. To exclude such a possibility, we next examined the combinatorial effect of GSKJ4 with these standard chemotherapeutic agents on NSCLC cells. Exposure of the NSCLC cell lines to cisplatin and paclitaxel over ranges of concentrations revealed that A549 was sensitive, whereas H1299 and PC9 were relatively resistant to both drugs (Figure 5A and $\mathrm{B}$ ). We then treated the NSCLC cell lines with cisplatin or paclitaxel in combination with GSKJ4 at a concentration at which GSKJ4 alone did not cause strong growth inhibition $(0.4 \mu \mathrm{M})$. Whereas the combination treatment was significantly superior to treatment with either alone in inhibiting the cell viability of A549 cells, the benefit of combination was not significant in H1299 and PC9 cells, except for the combination of GSKJ4 and paclitaxel in PC9 cells (Figure 5C and D). Thus, the results suggested that GSKJ4 may enhance the therapeutic effect of cisplatin and paclitaxel in a context-dependent manner and that, importantly, GSKJ4 at least may not interfere with the growth inhibitory effect of these drugs. 
A

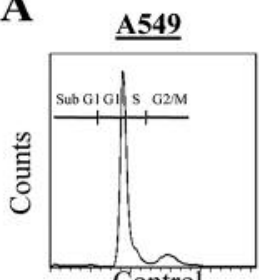

Control
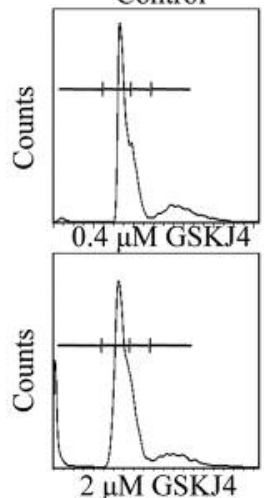

$2 \mu \mathrm{M}$ GSKJ4
$\underline{\mathrm{H1299}}$
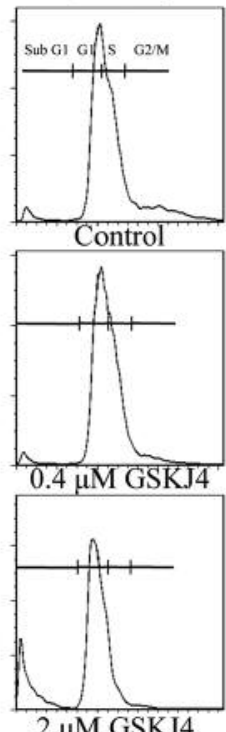

$2 \mu \mathrm{M}$ GSKJ4
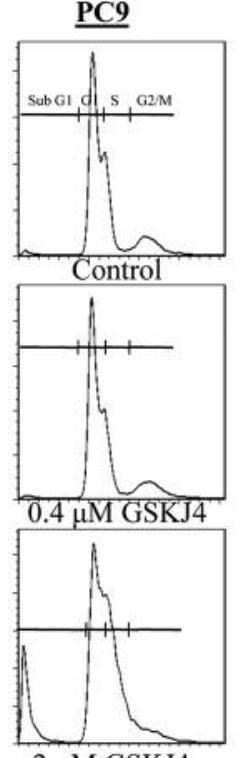

$2 \mu \mathrm{M}$ GSKJ4

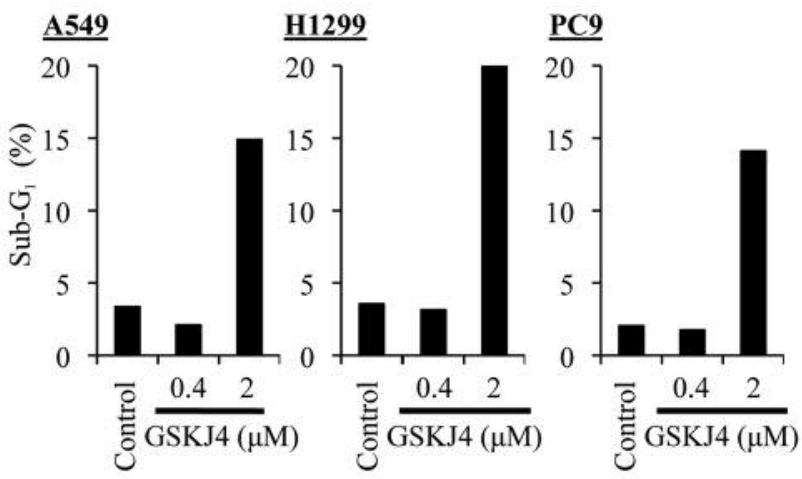

B

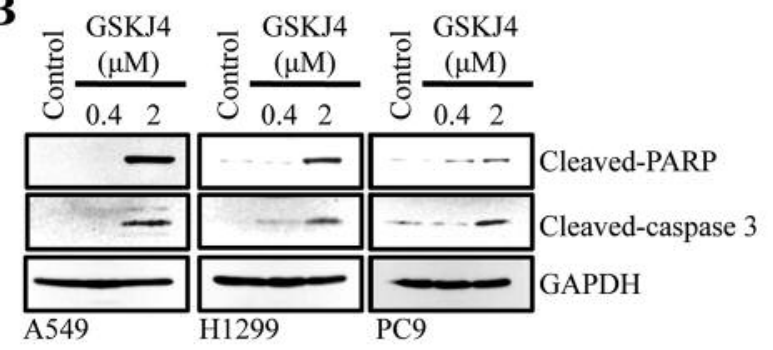

Figure 3. Increase in the sub-G $G_{1}$ population and caspase pathway activation after GSKJ4 treatment of non-small cell lung cancer (NSCLC) cells. (A) NSCLC cells treated with the indicated concentrations of GSKJ4 for 3 days were subjected to flow cytometry analysis of DNA content. Representative flow cytometry histograms (upper panels) and the percentage of the sub-G $G_{1}$ population (lower panels) are shown. (B) NSCLC cells treated as in (A) were subjected to immunoblot analysis of the indicated proteins.

Cooperative inhibition of NSCLC cell growth by GSKJ4 and metformin. Along with cisplatin and paclitaxel, we screened other drugs that are currently being used or may be used in the future in NSCLC treatment for possible synergy with GSKJ4. Metformin is an oral biguanide widely used in the management of type 2 diabetes that has been shown to have anticancer activity against NSCLC cells in vitro and in vivo (24-26). Only recently, a comprehensive meta-analysis of relevant publications demonstrated that metformin use is significantly associated with a favorable survival outcome of lung cancer patients with diabetes (27). We, therefore, tested the effect of metformin on NSCLC cells in combination with GSKJ4. At $1 \mathrm{mM}$, metformin moderately inhibited the growth of the three NSCLC cell lines without inducing cell death. When the NSCLC cell lines were treated with or without this concentration of metformin $(1 \mathrm{mM})$, in the presence $(0.4 \mu \mathrm{M}$; being itself, at best, modestly growthinhibitory) or absence of GSKJ4, the combination of GSKJ4 and metformin inhibited cell viability more effectively than treatment with either drug alone in all three NSCLC cell lines (Figure 6A), accompanied by increase in the proportion of dead cells (Figure 6B). Remarkably, the combinatorial growth inhibitory effect between GSKJ4 and metformin was more pronounced when their effects on the clonogenic outgrowth of NSCLC cells were evaluated in the colony formation assay (Figure 6C and D), possibly implying that the benefit of combination becomes more obvious at later time points.

\section{Discussion}

Global epigenetic changes, sometimes caused directly by mutations in genes encoding epigenetic regulators, are a characteristic feature of cancer $(28,29)$. Reflecting the pivotal role of histone methylation in epigenetic regulation (30), inhibitors targeting histone methyltransferases and demethylases are being developed as anticancer agents, some of which have already entered clinical trials $(3,31)$. GSKJ4 is a cell-permeable inhibitor of histone H3K27 demethylases, whose anticancer activity has been demonstrated in pediatric brainstem glioma and T-ALL, cancers associated with mutations in genes that directly affect H3K27 methylation (7-9). Although we have recently reported that GSKJ4 can target ovarian cancer stem cells (14), it still remains unclear whether the anticancer activity of GSKJ4 is specific to limited types of cancers, i.e., primarily those with mutations in epigenetics-related genes, or whether GSKJ4 could target a broader spectrum of cancers. Here, in this study, we demonstrated for the first time that GSKJ4 exerts potent anticancer activity against cell lines derived from NSCLC. Given that NSCLC has not been associated with genetic alterations directly affecting H3K27 methylation, our finding may provide a rationale to encourage exploration of the 

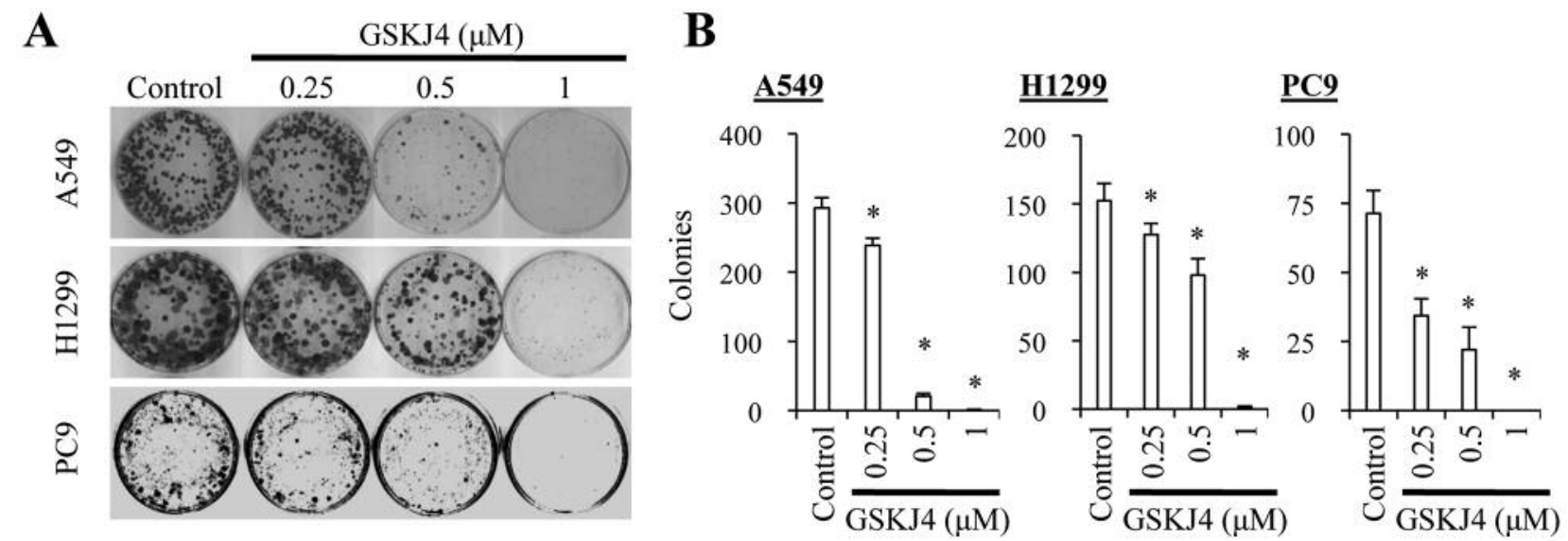

Figure 4. Suppression of clonogenic outgrowth of non-small cell lung cancer (NSCLC) cells by GSKJ4. NSCLC cells treated with the indicated concentrations of GSKJ4 for 3 days were cultured for another 1 week in the absence of GSKJ4 for colony formation assay. (A) Images of a representative experiment. (B) Graphs showing the number of colonies. Values represent means $+S D$ from triplicate samples of a representative experiment repeated with similar results. ${ }^{*} p<0.05$.

potential of GSKJ4 as an anticancer agent against a wider range of cancers than previously thought. The NSCLC cell lines used in this study were A549 (poorly differentiated adenocarcinoma with mutated KRAS, wild-type (wt) TP53 and wt EGFR), H1299 (poorly differentiated adenocarcinoma with wt KRAS, homozygous deletion of TP53 and wt EGFR) and PC9 (well differentiated adenocarcinoma with wt KRAS, wt TP53 and mutated EGFR) (32-38). Although A549 appeared to be somewhat more sensitive than the other two, GSKJ4 quite effectively inhibited the growth of all three cell lines at $2 \mu \mathrm{M}$, a concentration that did not affect the growth of normal human fibroblasts, which may imply that GSKJ4 exerts its anticancer effect irrespective of the genetic status of the KRAS, $T P 53$ and EGFR genes. Since it has been reported that less differentiated NSCLC tumors are associated with lower H3K27me3 expression, which may possibly be an indicator of sensitivity to GSKJ4 $(8,14,15)$, we initially expected that PC9, derived from a well differentiated adenocarcinoma, would have a higher H3K27me3 level and, therefore, be less sensitive to GSKJ4 than the other two derived from poorly differentiated adenocarcinomas. However, the results indicated that this was not actually the case; all three NSCLC cell lines had low global levels of H3K27me3 and were similarly sensitive to GSKJ4. While our findings are, thus, in support of the idea that cancer cells with low H3K27me3 levels are sensitive to GSKJ4, the question of whether there is an association between $\mathrm{H} 3 \mathrm{~K} 27 \mathrm{me} 3$ expression and GSKJ4 sensitivity still remains to be fully answered and is open to future investigations. It was also noteworthy that GSKJ4 quite effectively inhibited the growth of H1299 and PC9, both of which showed substantial resistance to cisplatin and paclitaxel. Thus, GSKJ4 might prove to be beneficial in treating NSCLC resistant to these drugs. Collectively, our findings suggest that GSKJ4 may be a promising anti-cancer agent for the treatment of NSCLC and, possibly, of a wide range of human cancers.

Unlike pathway-specific inhibitors, GSKJ4 is unique in that it could affect genome-wide H3K27 methylation as an inhibitor of $\mathrm{H} 3 \mathrm{~K} 27$ demethylases and, thus, cause generalized alterations in gene transcription. We, therefore, tested the impact of GSKJ4 treatment on the sensitivity of NSCLC cells to cisplatin and paclitaxel, standard chemotherapeutic agents used in the treatment of NSCLC (39). The results indicated that, whereas the benefit of combination was readily appreciated in A549 cells, it was less pronounced or nil in the other two cell lines resistant to cisplatin and paclitaxel. Importantly, GSKJ4 at least did not interfere with the growth inhibitory effect of cisplatin and paclitaxel on NSCLC cells, implying that GSKJ4 could be safely used in combination with these drugs.

While searching for drugs that may be of benefit when used in combination with GSKJ4, we discovered that metformin cooperates with GSKJ4 to inhibit the growth of NSCLC cells. Although the mechanism underlying the observed cooperation between these drugs remains a complete enigma at this moment, the benefit of combination was clearly observed in all three NSCLC cell lines examined, suggesting that the mechanism of cooperation is robust against genetic alterations frequently observed in NSCLC (i.e., mutations in the KRAS, TP53 and EGFR genes). Intriguingly, metformin is now drawing increasing attention as a cancer stem cell-targeting drug capable of inducing cancer stem cell death and/or differentiation into 

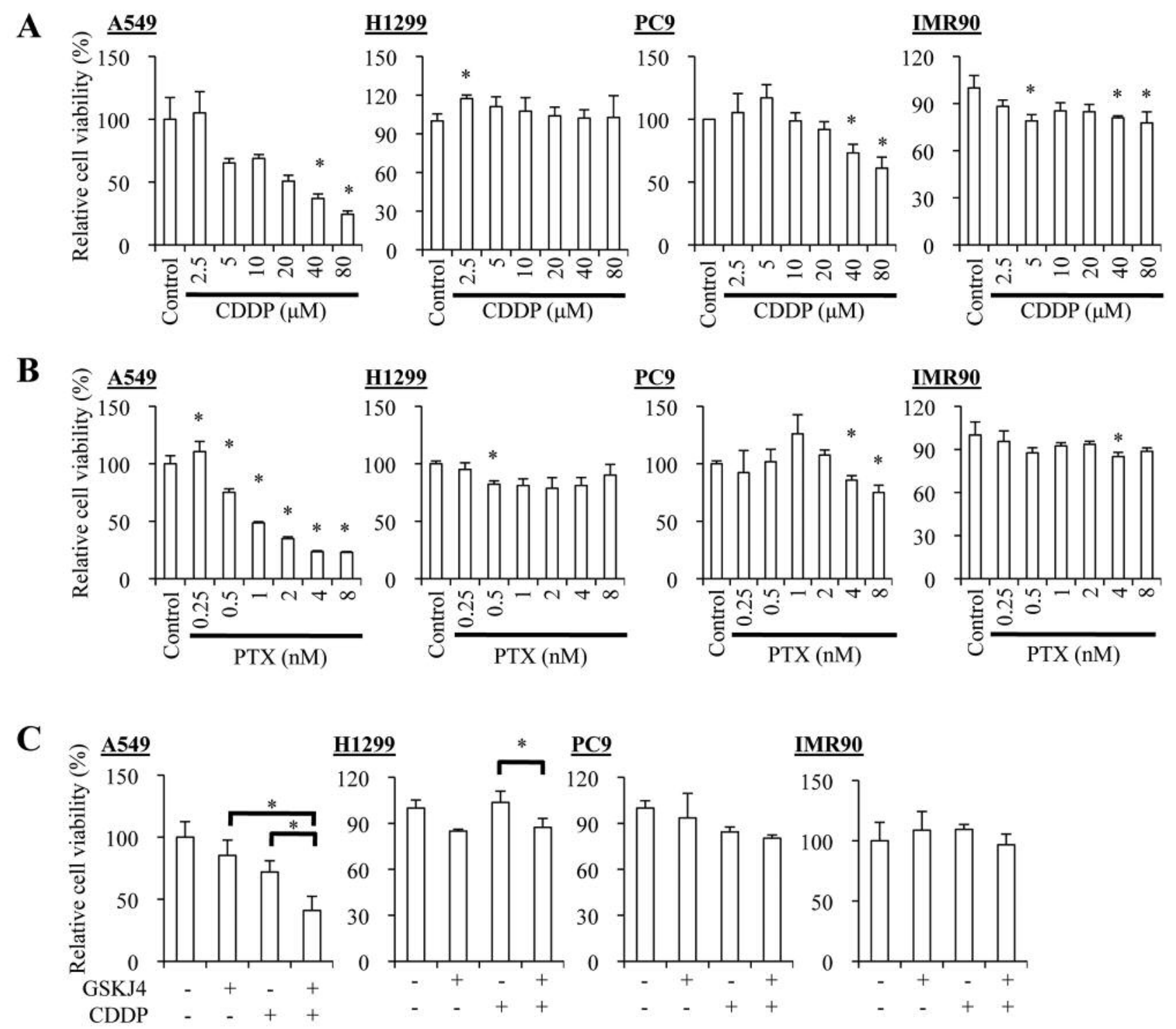

\section{IMR90}
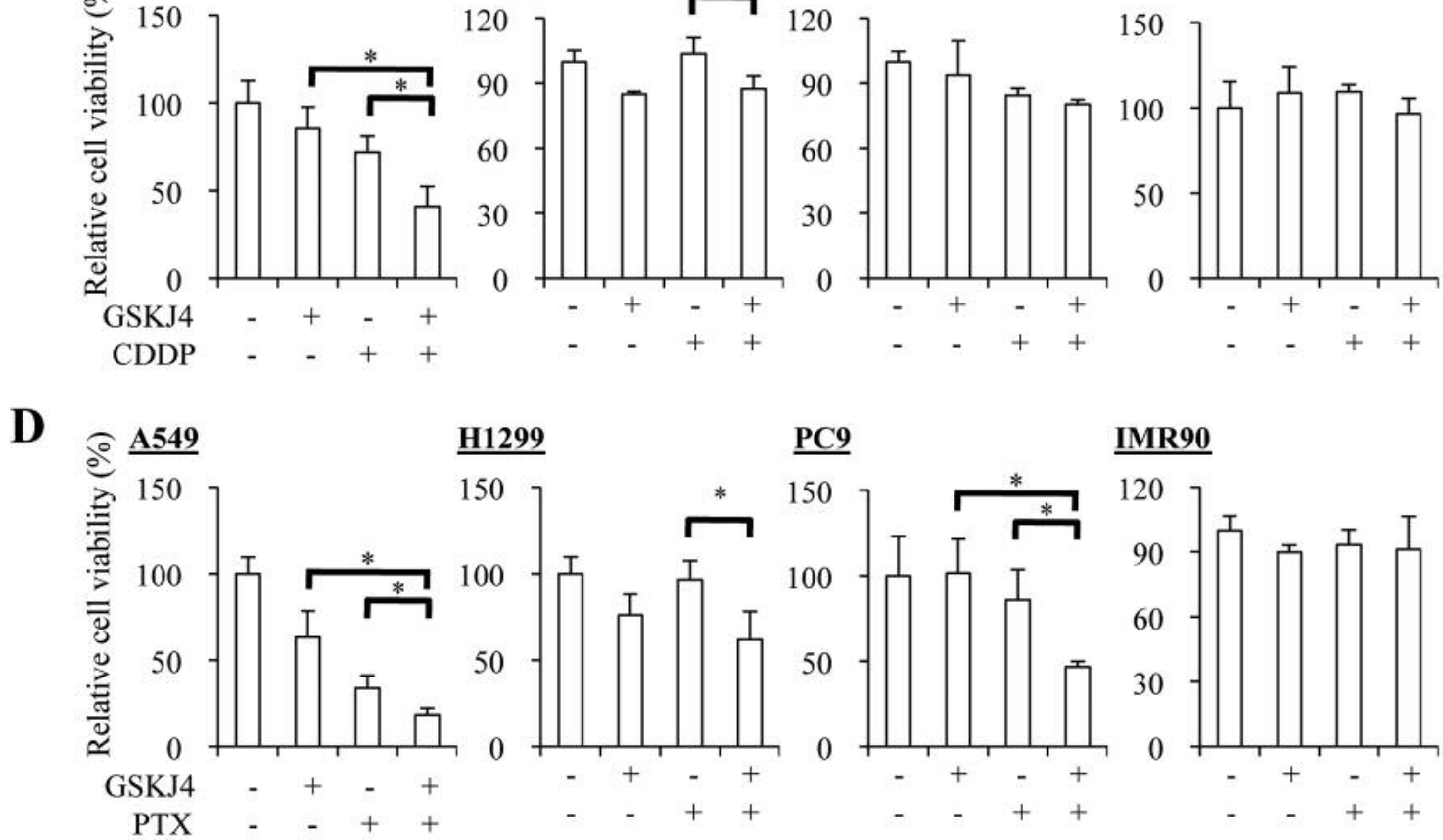

IMR90

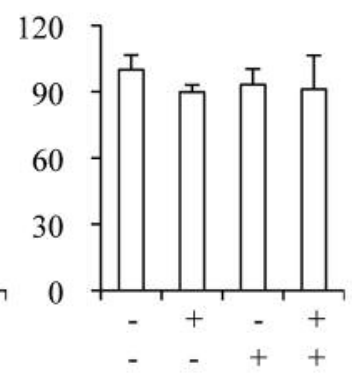

Figure 5. The effect of GSKJ4 on the sensitivity of non-small cell lung cancer (NSCLC) cells to cisplatin (CDDP) and paclitaxel (PTX). The indicated cells were treated with the indicated concentrations of CDDP $(A)$ or PTX $(B)$ for 3 days and subjected to the cell viability assay using WST-8. The indicated cells treated with or without $10 \mu \mathrm{M}$ of CDDP $(C)$ or $2 n M$ of PTX $(D)$ in the absence or presence of GSKJ4 (0.4 $\mu M)$ for 3 days were subjected to the cell viability assay using WST-8. In $(A)$ through $(D)$, values represent means $+S D$ from triplicate samples of a representative experiment repeated with similar results. ${ }^{*} p<0.05$. 
A

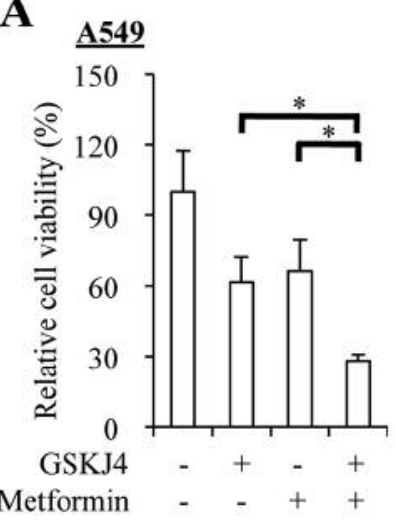

B

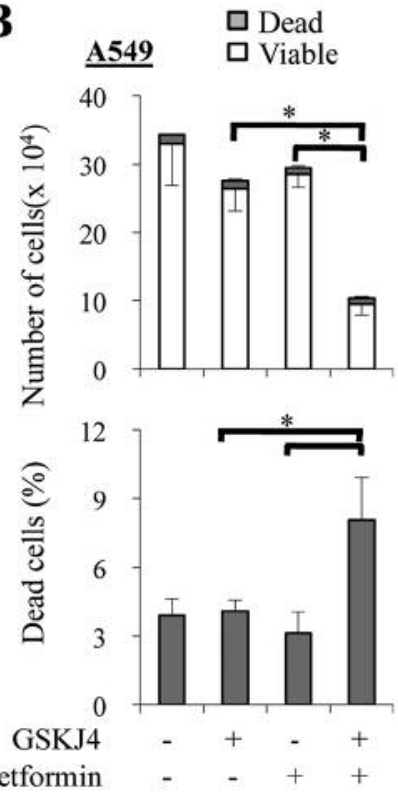

C

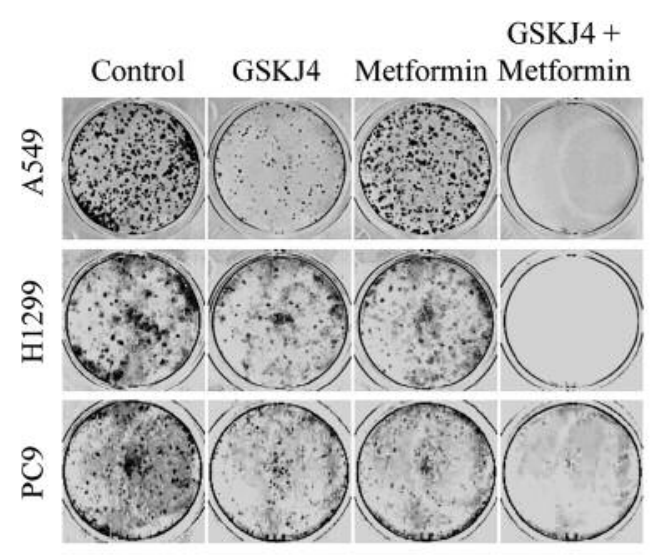

$\underline{\text { PC9 }}$

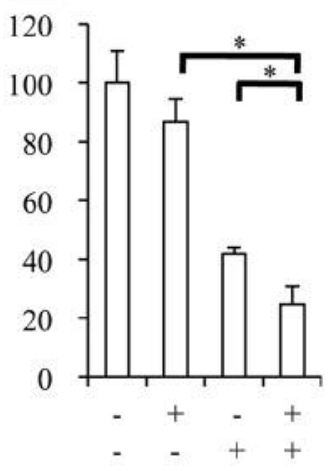

\section{$\underline{\text { IMR90 }}$}

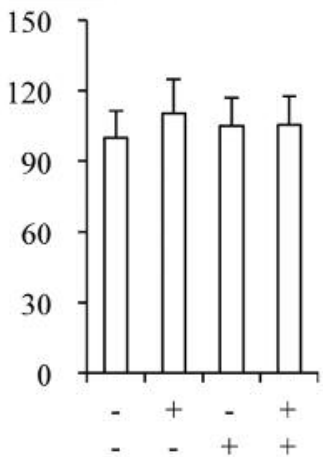

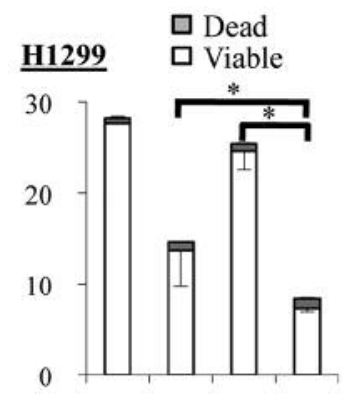
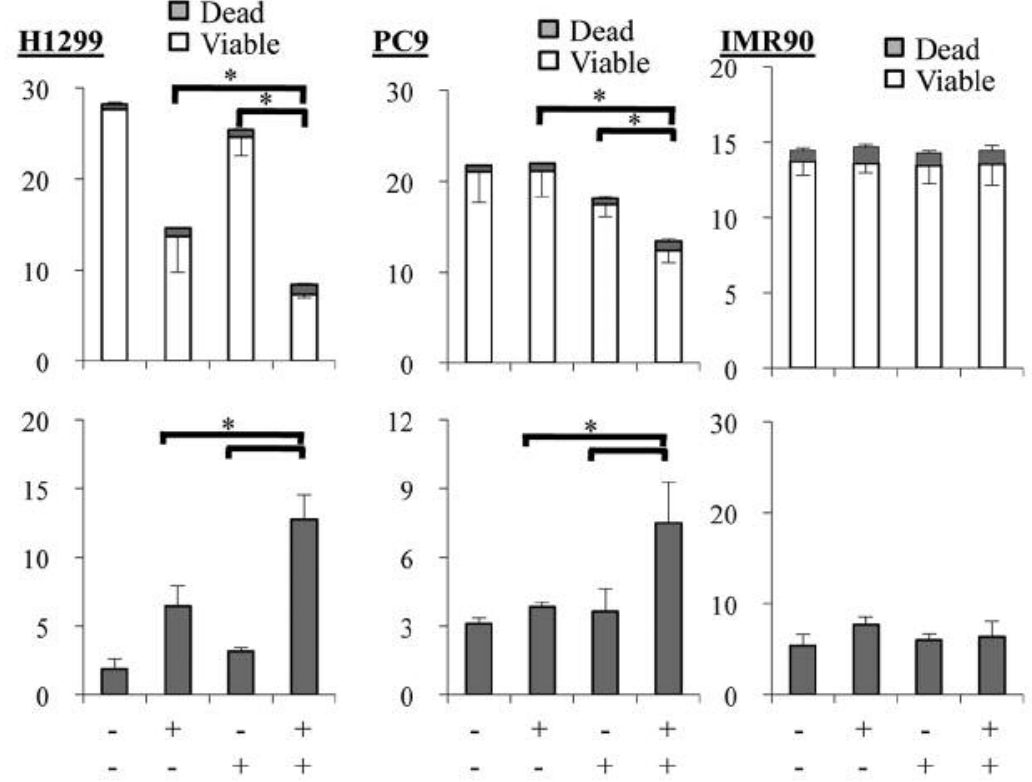

D

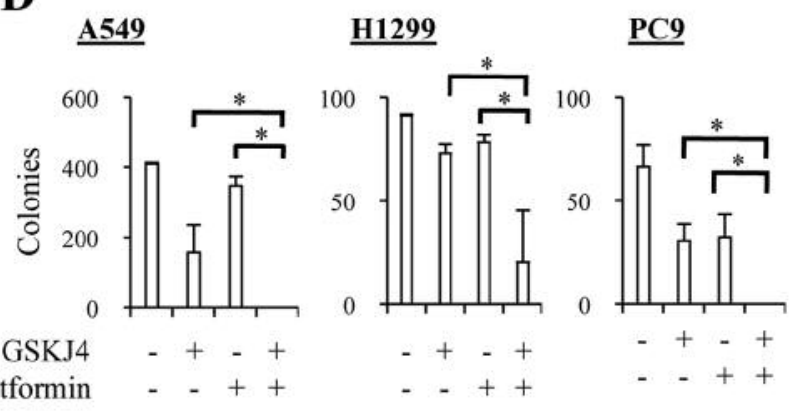

Figure 6. Cooperative inhibition of non-small lung cancer (NSCLC) cell growth by GSKJ4 and metformin. The indicated cells treated with or without metformin $(1 \mathrm{mM})$ in the absence or presence of GSKJ4 $(0.4 \mu \mathrm{M})$ for 3 days were subjected to the cell viability assay using WST-8 (A) or to the cell death assay based on trypan blue dye exclusion method $(B)$. In $(B)$, the number of viable and dead cells (upper panels) and the percentage of dead cells (lower panels) are shown. The NSCLC cells treated with the indicated combinations of drugs as in (A) and (B) for 3 days were cultured for another 1 week in the absence of drugs for colony formation assay. (C) Images of a representative experiment. (D) Graphs showing the number of colonies. In $(A),(B)$ and $(D)$, values represent means $\pm S D$ from triplicate samples of a representative experiment repeated with similar results. $* p<0.05$. 
non-cancer stem cells in a variety of human cancers, including NSCLC (40-43). Although the effect of GSKJ4 on cancer stem cells of NSCLC remains to be investigated, we have recently demonstrated that GSKJ4 can target and eliminate ovarian cancer stem cells (14). In this regard, it would be of interest and benefit to investigate the effect of GSKJ4 on cancer stem cells of NSCLC alone or in combination with metformin.

In conclusion, this study has demonstrated the potent anticancer activity of GSKJ4 against NSCLC cells. It has also been shown that GSKJ4 can be used in combination with cisplatin and paclitaxel and that concomitant use of metformin may enhance the anticancer activity of GSKJ4. Apparently, these promising in vitro findings warrant future preclinical studies involving animal models of NSCLC to evaluate the therapeutic impact of GSKJ4 in the treatment of NSCLC. The reported results also imply that the anti-cancer activity of GSKJ4 may not necessarily be specific to cancers with frequent mutations in genes implicated in epigenetic regulation and that GSKJ4 may be effective against a broader spectrum of cancers than previously assumed.

\section{Conflicts of Interest}

The Authors declare no conflict of interest.

\section{Acknowledgements}

The Authors would like to thank Ms. Eriko Watanabe and Ms. Asuka Sugai for their technical and secretarial contributions to this study, respectively. This work was supported by Grants-in-Aid for Scientific Research, for Challenging Exploratory Research and for Young Scientists from the Ministry of Education, Culture, Sports, Science and Technology of Japan.

\section{References}

1 Ezponda T and Licht JD: Molecular pathways: deregulation of histone h3 lysine 27 methylation in cancer-different paths, same destination. Clin Cancer Res 20: 5001-5008, 2014.

2 Li J, Zhu S, Ke XX and Cui H: Role of several histone lysine methyltransferases in tumor development. Biomed Rep 4: 293 299, 2016.

3 McGrath $\mathrm{J}$ and Trojer P: Targeting histone lysine methylation in cancer. Pharmacol Ther 150: 1-22, 2015.

4 Yi X, Jiang XJ, Li XY and Jiang DS: Histone methyltransferases: novel targets for tumor and developmental defects. Am J Transl Res 7: 2159-2175, 2015.

5 Maes T, Carceller E, Salas J, Ortega A and Buesa C: Advances in the development of histone lysine demethylase inhibitors. Curr Opin Pharmacol 23: 52-60, 2015.

6 Kruidenier L, Chung CW, Cheng Z, Liddle J, Che K, Joberty G, Bantscheff M, Bountra C, Bridges A, Diallo H, Eberhard D, Hutchinson S, Jones E, Katso R, Leveridge M, Mander PK, Mosley J, Ramirez-Molina C, Rowland P, Schofield CJ, Sheppard RJ, Smith JE, Swales C, Tanner R, Thomas P, Tumber A, Drewes G,
Oppermann U, Patel DJ, Lee K and Wilson DM: A selective jumonji H3K27 demethylase inhibitor modulates the proinflammatory macrophage response. Nature 488: 404-408, 2012.

7 Grasso CS, Tang Y, Truffaux N, Berlow NE, Liu L, Debily MA, Quist MJ, Davis LE, Huang EC, Woo PJ, Ponnuswami A, Chen S, Johung TB, Sun W, Kogiso M, Du Y, Qi L, Huang Y, HuttCabezas M, Warren KE, Le Dret L, Meltzer PS, Mao H, Quezado M, van Vuurden DG, Abraham J, Fouladi M, Svalina MN, Wang N, Hawkins C, Nazarian J, Alonso MM, Raabe EH, Hulleman E, Spellman PT, Li XN, Keller C, Pal R, Grill J and Monje M: Functionally defined therapeutic targets in diffuse intrinsic pontine glioma. Nat Med 21: 555-559, 2015.

8 Hashizume R, Andor N, Ihara Y, Lerner R, Gan H, Chen X, Fang D, Huang X, Tom MW, Ngo V, Solomon D, Mueller S, Paris PL, Zhang Z, Petritsch C, Gupta N, Waldman TA and James CD: Pharmacologic inhibition of histone demethylation as a therapy for pediatric brainstem glioma. Nat Med 20: 13941396, 2014.

9 Ntziachristos P, Tsirigos A, Welstead GG, Trimarchi T, Bakogianni S, Xu L, Loizou E, Holmfeldt L, Strikoudis A, King B, Mullenders J, Becksfort J, Nedjic J, Paietta E, Tallman MS, Rowe JM, Tonon G, Satoh T, Kruidenier L, Prinjha R, Akira S, Van Vlierberghe P, Ferrando AA, Jaenisch R, Mullighan CG and Aifantis I: Contrasting roles of histone 3 lysine 27 demethylases in acute lymphoblastic leukaemia. Nature 514: 513-517, 2014.

10 Bender S, Tang Y, Lindroth AM, Hovestadt V, Jones DT, Kool M, Zapatka M, Northcott PA, Sturm D, Wang W, Radlwimmer B, Hojfeldt JW, Truffaux N, Castel D, Schubert S, Ryzhova M, Seker-Cin H, Gronych J, Johann PD, Stark S, Meyer J, Milde T, Schuhmann M, Ebinger M, Monoranu CM, Ponnuswami A, Chen S, Jones C, Witt O, Collins VP, von Deimling A, Jabado N, Puget S, Grill J, Helin K, Korshunov A, Lichter P, Monje M, Plass C, Cho YJ and Pfister SM: Reduced H3K27me3 and DNA hypomethylation are major drivers of gene expression in K27M mutant pediatric high-grade gliomas. Cancer Cell 24: 660-672, 2013.

11 Chan KM, Fang D, Gan H, Hashizume R, Yu C, Schroeder M, Gupta N, Mueller S, James CD, Jenkins R, Sarkaria J and Zhang $\mathrm{Z}$ : The histone $\mathrm{H} 3.3 \mathrm{~K} 27 \mathrm{M}$ mutation in pediatric glioma reprograms H3K27 methylation and gene expression. Genes Dev 27: 985-990, 2013.

12 Lewis PW, Muller MM, Koletsky MS, Cordero F, Lin S, Banaszynski LA, Garcia BA, Muir TW, Becher OJ and Allis CD: Inhibition of PRC2 activity by a gain-of-function H3 mutation found in pediatric glioblastoma. Science 340: 857-861, 2013.

13 Venneti S, Garimella MT, Sullivan LM, Martinez D, Huse JT, Heguy A, Santi M, Thompson CB and Judkins AR: Evaluation of histone 3 lysine 27 trimethylation (H3K27me3) and enhancer of Zest 2 (EZH2) in pediatric glial and glioneuronal tumors shows decreased H3K27me3 in H3F3A K27M mutant glioblastomas. Brain Pathol 23: 558-564, 2013.

14 Sakaki H, Okada M, Kuramoto K, Takeda H, Watarai H, Suzuki S, Seino S, Seino M, Ohta T, Nagase S, Kurachi H and Kitanaka C: GSKJ4, A Selective Jumonji H3K27 Demethylase Inhibitor, Effectively Targets Ovarian Cancer Stem Cells. Anticancer Res 35: 6607-6614, 2015.

15 Chen X, Song N, Matsumoto K, Nanashima A, Nagayasu T, Hayashi T, Ying M, Endo D, Wu Z and Koji T: High expression of trimethylated histone $\mathrm{H} 3$ at lysine 27 predicts better prognosis in non-small cell lung cancer. Int J Oncol 43: 1467-1480, 2013. 
16 Pellakuru LG, Iwata T, Gurel B, Schultz D, Hicks J, Bethel C, Yegnasubramanian S and De Marzo AM: Global levels of H3K27me3 track with differentiation in vivo and are deregulated by MYC in prostate cancer. Am J Pathol 181: 560-569, 2012.

17 Wei Y, Xia W, Zhang Z, Liu J, Wang H, Adsay NV, Albarracin C, Yu D, Abbruzzese JL, Mills GB, Bast RC, Jr., Hortobagyi GN and Hung MC: Loss of trimethylation at lysine 27 of histone $\mathrm{H} 3$ is a predictor of poor outcome in breast, ovarian, and pancreatic cancers. Mol Carcinog 47: 701-706, 2008.

18 Hasan MK, Nafady A, Takatori A, Kishida S, Ohira M, Suenaga Y, Hossain S, Akter J, Ogura A, Nakamura Y, Kadomatsu K and Nakagawara A: ALK is a MYCN target gene and regulates cell migration and invasion in neuroblastoma. Sci Rep 3: 3450, 2013.

19 Makinoshima H, Takita M, Matsumoto S, Yagishita A, Owada $\mathrm{S}$, Esumi $\mathrm{H}$ and Tsuchihara K: Epidermal growth factor receptor (EGFR) signaling regulates global metabolic pathways in EGFRmutated lung adenocarcinoma. J Biol Chem 289: 20813-20823, 2014.

20 Suzuki S, Okada M, Shibuya K, Seino M, Sato A, Takeda H, Seino S, Yoshioka $\mathrm{T}$ and Kitanaka C: JNK suppression of chemotherapeutic agents-induced ROS confers chemoresistance on pancreatic cancer stem cells. Oncotarget 6: 458-470, 2015.

21 Okada M, Shibuya K, Sato A, Seino S, Suzuki S, Seino M and Kitanaka C: Targeting the K-Ras--JNK axis eliminates cancer stem-like cells and prevents pancreatic tumor formation. Oncotarget 5: 5100-5112, 2014.

22 Okada M, Sato A, Shibuya K, Watanabe E, Seino S, Suzuki S, Seino M, Narita Y, Shibui S, Kayama T and Kitanaka C: JNK contributes to temozolomide resistance of stem-like glioblastoma cells via regulation of MGMT expression. Int J Oncol 44: 591599,2014

23 Seino M, Okada M, Sakaki H, Takeda H, Watarai H, Suzuki S, Seino S, Kuramoto K, Ohta T, Nagase S, Kurachi $\mathrm{H}$ and Kitanaka C: Time-staggered inhibition of JNK effectively sensitizes chemoresistant ovarian cancer cells to cisplatin and paclitaxel. Oncol Rep 35: 593-601, 2016.

24 Ashinuma H, Takiguchi Y, Kitazono S, Kitazono-Saitoh M, Kitamura A, Chiba T, Tada Y, Kurosu K, Sakaida E, Sekine I, Tanabe N, Iwama A, Yokosuka O and Tatsumi K: Antiproliferative action of metformin in human lung cancer cell lines. Oncol Rep 28: 8-14, 2012.

25 Foretz M, Guigas B, Bertrand L, Pollak M and Viollet B: Metformin: from mechanisms of action to therapies. Cell Metab 20: 953-966, 2014.

26 Storozhuk Y, Hopmans SN, Sanli T, Barron C, Tsiani E, Cutz JC, Pond G, Wright J, Singh G and Tsakiridis T: Metformin inhibits growth and enhances radiation response of non-small cell lung cancer (NSCLC) through ATM and AMPK. Br J Cancer 108: 2021-2032, 2013.

27 Wan G, Yu X, Chen P, Wang X, Pan D, Wang X, Li L, Cai X and Cao F: Metformin therapy associated with survival benefit in lung cancer patients with diabetes. Oncotarget 2016.

28 Plass C, Pfister SM, Lindroth AM, Bogatyrova O, Claus R and Lichter P: Mutations in regulators of the epigenome and their connections to global chromatin patterns in cancer. Nat Rev Genet 14: 765-780, 2013.

29 Rodriguez-Paredes $\mathrm{M}$ and Esteller M: Cancer epigenetics reaches mainstream oncology. Nat Med 17: 330-339, 2011.

30 Greer EL and Shi Y: Histone methylation: a dynamic mark in health, disease and inheritance. Nat Rev Genet 13: 343-357, 2012.
31 Morera L, Lubbert $\mathrm{M}$ and Jung $\mathrm{M}$ : Targeting histone methyltransferases and demethylases in clinical trials for cancer therapy. Clin Epigenetics 8: 57, 2016.

32 Chen FA, Repasky EA, Takita H, Schepart BS and Bankert RB: Cell surface glycoprotein associated with human lung tumors that is similar to but distinct from the epidermal growth factor receptor. Cancer Res 49: 3642-3649, 1989.

33 Han JY, Chung YJ, Park SW, Kim JS, Rhyu MG, Kim HK and Lee KS: The relationship between cisplatin-induced apoptosis and p53, bcl-2 and bax expression in human lung cancer cells. Korean J Intern Med 14: 42-52, 1999

34 Huang JQ, Liang HL, Zhang XC, Xie Z and Jin TE: Synergistic antitumor activity of pro-apoptotic agent PAC-1 with cisplatinum by the activation of CASP3 in pulmonary adenocarcinoma cell line H1299. Asia Pac J Clin Oncol 12: 41$51,2016$.

35 Li H, Schmid-Bindert G, Wang D, Zhao Y, Yang X, Su B and Zhou C: Blocking the PI3K/AKT and MEK/ERK signaling pathways can overcome gefitinib-resistance in non-small cell lung cancer cell lines. Adv Med Sci 56: 275-284, 2011.

36 Ohashi K, Sequist LV, Arcila ME, Moran T, Chmielecki J, Lin YL, Pan Y, Wang L, de Stanchina E, Shien K, Aoe K, Toyooka S, Kiura K, Fernandez-Cuesta L, Fidias P, Yang JC, Miller VA, Riely GJ, Kris MG, Engelman JA, Vnencak-Jones CL, DiasSantagata D, Ladanyi M and Pao W: Lung cancers with acquired resistance to EGFR inhibitors occasionally harbor BRAF gene mutations but lack mutations in KRAS, NRAS, or MEK1. Proc Natl Acad Sci USA 109: E2127-2133, 2012.

37 Onn A, Isobe T, Itasaka S, Wu W, O'Reilly MS, Ki Hong W, Fidler IJ and Herbst RS: Development of an orthotopic model to study the biology and therapy of primary human lung cancer in nude mice. Clin Cancer Res 9: 5532-5539, 2003.

38 Yang L, Zhou Y, Li Y, Zhou J, Wu Y, Cui Y, Yang G and Hong Y: Mutations of $\mathrm{p} 53$ and KRAS activate NF-kappaB to promote chemoresistance and tumorigenesis via dysregulation of cell cycle and suppression of apoptosis in lung cancer cells. Cancer Lett 357: 520-526, 2015.

39 Reck M, Heigener DF, Mok T, Soria JC and Rabe KF: Management of non-small-cell lung cancer: recent developments. Lancet 382: 709-719, 2013.

40 Iliopoulos D, Hirsch HA and Struhl K: Metformin decreases the dose of chemotherapy for prolonging tumor remission in mouse xenografts involving multiple cancer cell types. Cancer Res 71: 3196-3201, 2011

$41 \mathrm{Lv}$ J and Shim JS: Existing drugs and their application in drug discovery targeting cancer stem cells. Arch Pharm Res 38: 16171626, 2015.

42 Vallianou NG, Evangelopoulos A and Kazazis C: Metformin and cancer. Rev Diabet Stud 10: 228-235, 2013.

43 Zhang HH and Guo XL: Combinational strategies of metformin and chemotherapy in cancers. Cancer Chemother Pharmacol 2016. 